\title{
MULTIDIMENSIONAL EVALUATION OF USER INTERFACES USABILITY ENRICHED WITH DECISION SUPPORT SYSTEMS ANALYSIS
}

\author{
Mariana Carvalho, Orlando Belo and Saulo Silva \\ Universidade do Minho, Departamento de Informática, Braga, Portugal
}

\begin{abstract}
Interactive Systems' User Interfaces can be considered as a special type of decision support system, as it exposes system's internal logic for supporting users' decision-making processes. Several evaluation methods can be used for investigating if the behaviour of a user interface complies with the best practices of human interface design. This paper investigates how Decision Support Systems methods and tools might assist in the analysis of Interactive System's User Interfaces. A research instrument is designed, as well as a multidimensional view of the data is created and presented. This work presents an alternative demarche for extending usability measurements of interactive interfaces, seeking to assist system designers and administrators in maintaining and improving their systems.
\end{abstract}

\section{KEYWORDS}

Decision Support Systems, Interactive Systems, User Interfaces, Usability Evaluation, What-If Analysis

\section{INTRODUCTION}

Decision Support Systems (DSS) materialize a concept about the role of computers within the decision-making processes (Fick and Sprague, 2013). For some researchers, DSS represent a kind of interactive system, i.e., computer systems that managers use for accessing business data. Others focus on DSS as representing analytic models suited for decision-making processes. Regardless of the group and how they understand the concept, its importance is unquestionable, as it intercepts different fields of the modern world. If one looks to decision-making processes from a different angle, an especial kind of DSS is revealed. As interactive systems support interaction between humans and computers, for this reason it should provide a User Interface (UI). In this sense, we can define UI as the part of the system with which humans (the "user" in this context) come into contact, physically, perceptually and conceptually (Benyon, 2014). When such interfaces are graphical (GUI), they provide elements to control the system - e.g., buttons, screens, text boxes, sliders, etc. -, exposing to the user the processes behind the system under control. The user makes use of the UI intending to achieve a goal with the system. If the UI has flaws or problems, the goal is unachieved. Some systems have critical functions, such as medical, energy, aeronautical systems, and in such cases, are referred to as critical interactive systems. For those systems, errors and problems in the UI have the potential for causing losses of different nature, such as financial, environmental or social, which Leveson (2011) characterises simply as accidents. Different kinds of evaluations can be used for ensuring safe and effective operation of UI or special DSS.

In this work we focused our attention in a particular system UI: a university library Web site. Universities' libraries are among the most important resources for students and researchers, as they intend to provide curated and catalogued information for this public. Those libraries provide Web sites for consulting information. Providing a well-designed Web site then has major importance for universities and companies to support their strategic goals. Well-designed Web sites can be valuable tools for its users, fulfilling their needs and expectations and helping them to accomplish their tasks. Several criteria exist to define what a well-designed Web site is, such as reliability and security (Fernandez et. al., 2011); however, from the user point of view, Usability is an important aspect to consider (Djamasbi et. al., 2010; Okhovati et. al., 2017). 
Our work was about how to evaluate the referred library Web site, taking into account end user participation. Okhovati et. al., (2017) highlighted that end users expect the library Web site to be easy to use, efficient in performing a specific task and ensure their satisfaction when they use it. Therefore all efforts that can be deployed for ensure the correctness and way of working with the Web site are important, not only in terms of automatic or manual evaluations, considering human factors. This is why a multidimensional view of the usability evaluation might improve the analysis results, allowing for the extraction of additional information from the data, fulfilling the role of DSS for those interested in providing a well-designed UI. We propose the use of a data warehouse (DW) to receive and provide the referred multidimensional data view. Additionally, we applied What-if analysis for enriching the usability evaluation results. Therefore, the contributions of this paper are as follows: to provide a literature review for themes such as DSS, What-If and usability analysis, as well as to provide a clear understanding of how they are related. Our aim was to bring all those concepts without losing sight of its centrality for the evaluation of interactive computer system's interfaces, i.e., its importance on how they can be used for improving those interfaces. The remaining part of this paper is organised as follows: Section 2 addresses some background topics and related work about usability and DSS, Section 3 exposes some considerations about the experiment design, the implementation of the multidimensional and DSS analysis, and, finally, Section 4 presents some conclusions and research lines for future work.

\section{BACKGROUND}

The literature of libraries evaluation provides evidence that the majority of evaluation studies of digital libraries are related with usability (Kous et. al., 2018). Usability can be seen as a set of multiple constructs derived from various perspectives, such as effectiveness, efficiency, subjective pleasure, or memorability, with large focus on interface design (Jeng, 2006). Nielsen, who in the early 1990s, together with Rubin, developed usability engineering techniques for computer software design applied to Web design (Nielsen, 2003), establishes that usability "is a quality attribute that describes how easy user interfaces are to use" (Kous et. al., 2018). International Organization for Standardization (ISO), in its chapter 9241-11 about Ergonomics of human-system interaction, considers usability as "the extent to which a product can be used by a specified user to achieve specified goals with effectiveness, efficiency and satisfaction in a specified context of use" (ISO/IEC, 1998). More specifically, we can see effectiveness as a reference to the completeness at which users achieve specified goals, efficiency as an allusion to the resources used in completing a task, and satisfaction the construct that reveals positive attitudes toward using the system. The literature provides evidence of strong positive correlation between satisfaction with effectiveness and efficiency (Joo, 2010). Due to these findings, the construct of satisfaction was excluded from the framework used as research instrument. Instead of satisfaction, the construct of learnability is selected as part of the research instrument. This construct is based on software engineering aspects, such as the usability model proposed by Nielsen (Nielsen, 1994), which refers to how easy it is for casual users to learn a system, or ISO/IEC 9126 (ISO/IEC, 2001), referring to the capability of a software product for enabling users to learn how to use it.

The increase in business competitiveness has led to the need of obtaining strategic information, due to its value. In order to achieve this, one possibility was to re-signify pre-existing data in the companies, obtaining multidimensional information from it that might help in a decision-making process. DSS are then characterised by their mission to improve the decision-making process, by providing either interactive systems that managers can use to access data, or analytic models suited for the decision-making process. From the need to re-signify data, the concept of data warehouse (DW) emerged. Muntean \& Târnăveanu (2012) highlights that a DW is defined as a special kind of a database, in which atomic data are gathered from several sources in a structured way for creating a multidimensional and oriented version of the corporative truths, which allows for precise initiatives to support decision making processes. There are several divergences about the best approach for defining DW architecture, in terms of quality, high performance or scalability. Ralph Kimball, for instance, supports the idea that each business area should freely implement its own databases, based on their requirements (Matouk \& Owoc, 2012). Bill Inmon in contrast, supports a top-down approach, in which the databases are developed according to the DW final project, i.e., a central scheme working as a model for the departments to develop their own databases (Breslin, 2004). 
The importance of usability is undeniable. It increases user satisfaction, efficiency and productivity and decreases costs (Mazumder, 2012). Usually, the evaluation of usability involves activities such as collecting, analysing and critiquing usability data (Ivory and Hearst, 1999). The analysis is a crucial phase in this process due to the importance of interpreting data and analysing results. What-If analysis is a technique that can help in this task. By helping the user to simulate scenarios based on human information - modelling a user interaction with a user interface is one of many advantages of the integration of What-If analysis simulation in usability evaluation processes.

Golfarelli, et. al. (2006) defines What-If analysis as a method that allows for decision makers to create hypothetical scenarios and analyse possible effects in the behaviour of a complex system caused by changing variables' values. In other words, this technology permits to assess beforehand what might happen in the business as result of manipulating parameters and changing what can be consider as a normal business behaviour without endangering real business. This technology ends up being a useful way for testing and validating business hypotheses and a safer solution to address any doubt, like for instance, answer the What-If type question "What if we pursue a new strategy?". What-If analysis also helps to ensure that the subsequent decisions will have some success, by helping the user to simulate the hypothetical scenarios and analyse the outcome. Moreover, it allows for analysing different scenarios and perspectives of business, anticipating some possible solutions. The process of What-If analysis is made using a simulation model. This model represents the real business model and can be composed by a set of scenarios based on historical data. The user is responsible to delineate the axis of analysis, the set of values for analysing and the set of values of the scenario to change according to his goals. To perform the What-If analysis, it is required to have an appropriate tool, which can perform this technology to get the new (altered) scenario. Goal seek is a Microsoft Office Excel's (Excel, 2019) built-in What-If analysis tool, which helps the user to answer What-If type questions by showing what could be the effects of changing a cells' value in a specific scenario. In other words, it determines what value a user should enter in an input cell to get the desired result in a cell that contains a formula. Goal seek receives a formula cell, the desired value and the cell to change in order to achieve the target and performs all the need calculations giving the user the wanted value. A symbolic example of how goal seek works (Figure 1 ) is about considering a retail company and a basic model. Giving the number of units sold (1500 units), retail price ( $\$ 15)$ and discount $(25 \%)$, using a calculation formula to calculate the total revenue reveals $\$ 16,875.00$. The main goal of this analysis is to discover how many units the retail company needs to sell to reach $\$ 25,000$ of revenue (Figure 1a). To do this, it is important to define the "Set cell", "To value" and "By changing cell" in the goal seek dialog box. The set cell is the revenue cell represented by D5 cell, and we intent to alter this cell to ' $\$ 25,000$ ', by changing the cell of the ' 1500 ' units sold represented by D2. After Goal Seek is performed (Figure 1b), the Excel informs that the Goal Seek provides a solution: 2222 units need to be sold to achieve the target value.
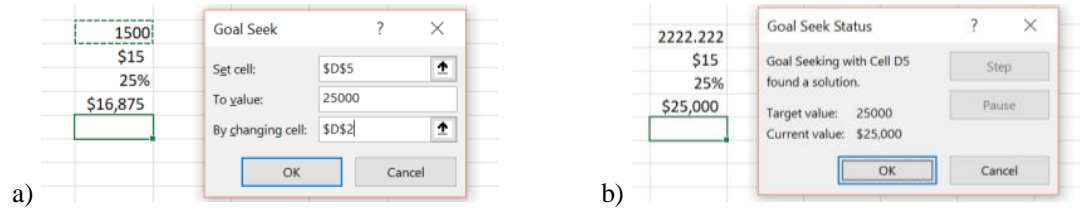

Figure 1. Goal-seek example (a) and results (b)

The literature of What-If analysis provides some relevant references about its use in usability evaluation. For instance, Hearst and Landay (1999) surveys a state of the art of automation of user interface usability evaluation and suggest the use of What-If analysis in an earlier development stage can help to avoid costly mistakes. A simulator named Monte Carlo (Rubinstein and Kroese, 2016), which is a probabilistic simulator model that uses What-If analysis and is frequently used in usability evaluations. Arh and Jerman-Blazic (2007) proposed a complex decision-making solution for the evaluation of learning management systems, by studying and analysing usability, applicability and adequacy of learning management systems. These authors suggest using What-If analysis in the learning management systems evaluation and analysis phase. Eklund et. al., (2008) implement a usability evaluation method for software development using eXtreme Programming (agile methodology for software development). During the usability evaluation setup, the authors use What-If analysis to simulate several types of analysis. What-If analysis is also referred in other Human-Computer Interaction (HCI) literature, such as in aviation safety, where Rungta et. al. (2013) presents a formal verification approach based on simulation and on model checking to guarantee the safety in human-machine systems. The models are 
created using Brahms, which uses What-if analysis and allows for modelling several components using simulation; and in discrete event simulation models with virtual reality integration, Turner et. al. (2016) uses What-If analysis in the experimentation and validation of the discrete event simulation model.

\section{EXPERIMENT DESIGN}

\subsection{Gathering, Preparing and Storing Data}

The word 'usability' refers to methods for improving ease-of-use during the design process. In general, the usability of a system has the potential to impact how users accomplish tasks in a system. To provide well-designed interactive systems, tools and methods are required for understanding the usability of user interfaces, as well as for improving them (Root and Draper, 1983). In this work, we adopted the usability evaluation model and associated evaluation survey tool proposed by Joo (2011), tailored to academic libraries Web sites. We decided to design our research instrument in the form of a research survey, which is used to obtain necessary data to analyse. The survey uses closed questions to collect the information, as opposed to open-ended questions, where the responder is free to give his own answers to the questions. In this case, we rely in the Likert scale to transform order points into a linear scale (Babbie, 1999) and to address two groups of information: 1) demographic information (filter questions), for exploring the characteristics of the different study groups; 2) research questions information, also referred as to usability evaluation instrument, directly related with the usability evaluation model in the context of academic libraries, proposed by Joo (2011). Typically the scale rating ranges from 5,7 and 9 points. We decided to use a 7 points scale (Table 1), starting with the alternative "I strongly disagree" (1 point), following additional six intervals, until the final interval designated "I totally agree" (7 points), respectively. The research survey was designed for collecting information in a monthly basis periodicity.

Table 1. Likert Scale defined for the research instrument (Babbie, 1999)

\begin{tabular}{c|c|c|c|c|c|c}
\hline $\begin{array}{c}\text { (1) I strongly } \\
\text { disagree }\end{array}$ & (2) Disagree & $\begin{array}{c}\text { (3) Slightly } \\
\text { disagree }\end{array}$ & $\begin{array}{c}\text { (4) I do not } \\
\text { agree or } \\
\text { disagree }\end{array}$ & $\begin{array}{c}\text { (5) Slightly } \\
\text { agree }\end{array}$ & $\begin{array}{c}\text { (7) I totally } \\
\text { agree }\end{array}$ \\
\hline $\begin{array}{c}\text { (Do not answer } \\
\text { at all to the } \\
\text { required) }\end{array}$ & $\begin{array}{c}\text { (Serves with } \\
\text { failed the } \\
\text { minimum } \\
\text { required) }\end{array}$ & $\begin{array}{c}\text { (Meets partially } \\
\text { the } \\
\text { expectations) }\end{array}$ & $\begin{array}{c}\text { (Neither agree } \\
\text { or disagree) }\end{array}$ & $\begin{array}{c}\text { (Meets partially } \\
\text { the } \\
\text { expectations) }\end{array}$ & $\begin{array}{c}\text { (Meets } \\
\text { completely the } \\
\text { expectations) }\end{array}$ & $\begin{array}{c}\text { (Above the } \\
\text { expectations) }\end{array}$ \\
\hline
\end{tabular}

The research instrument was hosted in a specific computational platform for data gathering and treatment, where university's staff (including master and $\mathrm{PhD}$ students, as well as researchers) was invited to participate in the research. Each respondent is required to answer six questions regarding each of the three research constructs (properties), namely effectiveness, efficiency and learnability. A number of thirty-five respondents $(n=35)$ were able to participate. All the answers were collect using a specific Web form and the correspondent data stored in an operational system supported by MySQL (MySQL, 2019).

Based on the data collected and the requisites previously established for user satisfaction analysis we designed a decision support data structure especially conceived for this usability case analysis. This structure includes all the analysis dimensions we considered to be the most relevant for the case, namely "Date", a temporal dimension, "Question", which supports the questions themselves, "Respondent", where we characterized in terms of frequency, skill, or gender, who answered the usability question, and "Property", the dimension that simply describes the property associated with a particular question. These four dimensions were materialized in four relational tables ("Date_Dim", "Question_Dim", "Respondent Dim", and "Property_Dim") that jointly with a fifth table - a fact table ("Usability_Fact") - formed a relational star-schema (Figure 2), one of the most typical configuration for a data warehouse. The definition of the granularity level of the fact table is an important aspect in the design of the data warehouse, as it impacts directly its performance and analysis capacity. A very high level of granularity might reduce system performance, once it stores a higher number of registers. A very low level of granularity might affect the analysis, since the data are usually shortened. The proposed grain of the analysis is then the classification given by each of the respondents to the specific questions of the research instrument. The field "ScaleValues" in the fact table "Usability_Fact" is responsible for storing this specific information. 


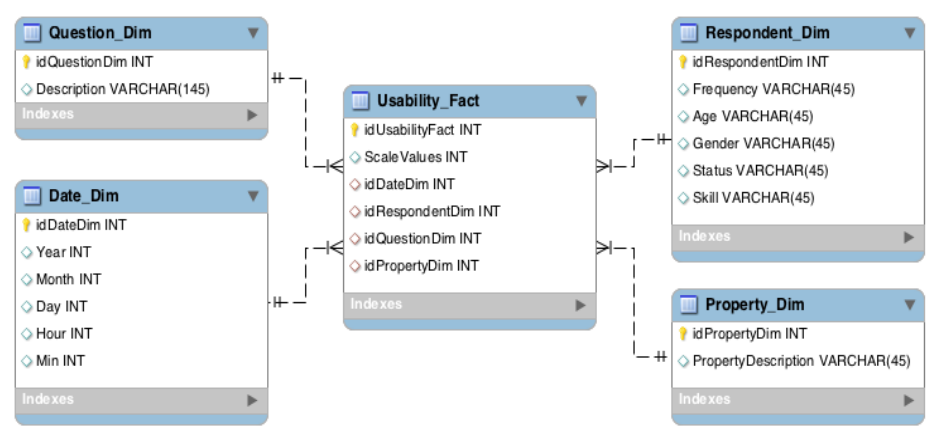

Figure 2. The usability star-schema of the data warehouse

Obtaining the multidimensional data view of the collected data implies the extraction, transformation and loading the data received from the Web-based form into the data warehouse. To accomplish this task we have developed an ETL (extract-transform-load) process. This process is crucial and needs to be performed with attention to ensure the correct introduction of the data into the data warehouse structures, in order that they can be used to identify new strategic information (e.g., tendencies), which can be used to improve the decision-making process. ETL operations are usually performed by a set of tools known as back-end tools, in a reference to the tools used by the engineers in charge of maintenance and management operations of such kind of systems, as opposed to front-end tools, which managers and decision-makers make use for activities such as consulting reports, graphics and information using the DW system. According to Kimbal (1996), the main operations performed by the back-end tools are: 1) extraction of data from internal and external sources; 2) cleaning or normalization of the extracted data; 3) loading data into the data warehouse; and 4) updating data (refresh). During the migration process, different types of needs might exist until the required result is achieved. Therefore, the utilisation of different back-end tools in different phases of the project is frequent. In our case, we choose to work with two, namely: Pentaho Data Integration (Pentaho, 2019), often referred to as Kettle, which is the Pentaho component in charge of ETL activities (Casters et. al., 2010); and MySQL Workbench (MySQL Workbench, 2019), which is the database management tool available for MySQL. In Figure 3 we can see the BPMN (Business Process Model and Notation) model proposed to execute the ETL operations. Basically, this process was organized in two different parts. In the first part, the Kettle tool was used to normalise and load the data from the operational system into the data warehouse, namely to populate the dimensions tables and to create data mappings in a staging area, which was used to support all the transformation tasks integrated in the ETL process. In the second part, all the data consolidation tasks are performed, and the fact table is populated.

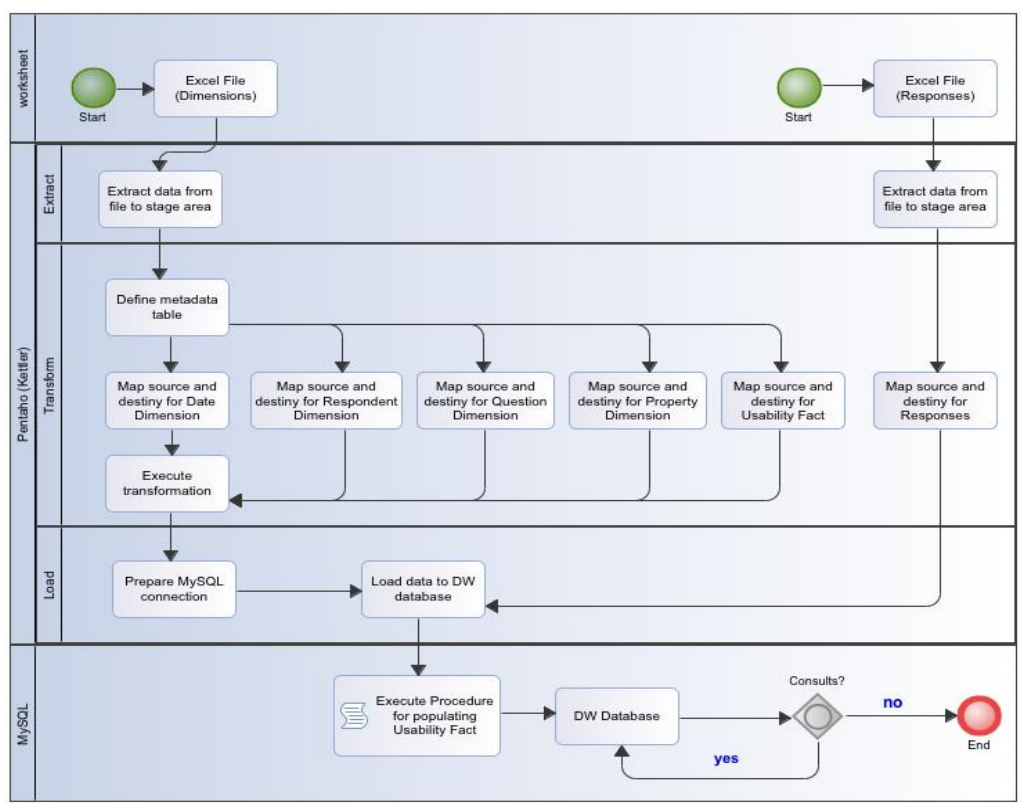

Figure 3. The BPMN Model of the ETL Process 


\subsection{Usability Analysis}

Having the data warehouse fully implemented as a DSS, methods and tools can be used to analyse the results, enriching the value of the multidimensional information. What-If analysis is a valuable method to use in this case. In this work, we use it to verify the outcome of three possible application scenarios. For instance, let's consider the representation for aggregated value of each construct, namely effectiveness, efficiency and learnability. After the data warehouse implementation, those representations can help the designer to understand the user perception for each construct. Therefore, the final evaluation given for the constructs is composed by the pair [order point/representation in the linear scale], in which the order point is obtained by verifying the mode value of each construct, and the representation in the linear scale can be obtained by consulting Table 1 . Effectiveness and Efficiency constructs are scored 4.0, whereas its respective representation in the linear scale is "Neither agree or disagree" to the construct questions. Learnability construct is score 5.0, translating to "Meets partially the expectations" in the linear scale of the construct questions. Thus the overall system final evaluation represents the value "I do not agree or disagree" in the linear scale. Using the previous rationale, the designer could hypothetically wonder how the system score behaves when one of the constructs is scored maximum classification, indicating final users "totally agrees" to the construct questions. Therefore, three applications scenarios are presented: i) effectiveness scores 7, ii) efficiency scores 7 and iii) learnability scores 7. Figure 4a depicts the scenario manager, a tool that works as an interface to the Goal Seek tool. The outcome of the analysis, shown in Figure 4b, presents the possible effects changes in the behaviour of the three scenarios, which are respectively 5.0, 7.0 and 6.0. Based on this outcome, a designer might justify his decisions to change policies or allocate resources to best suit the strategy of improving the Web site.
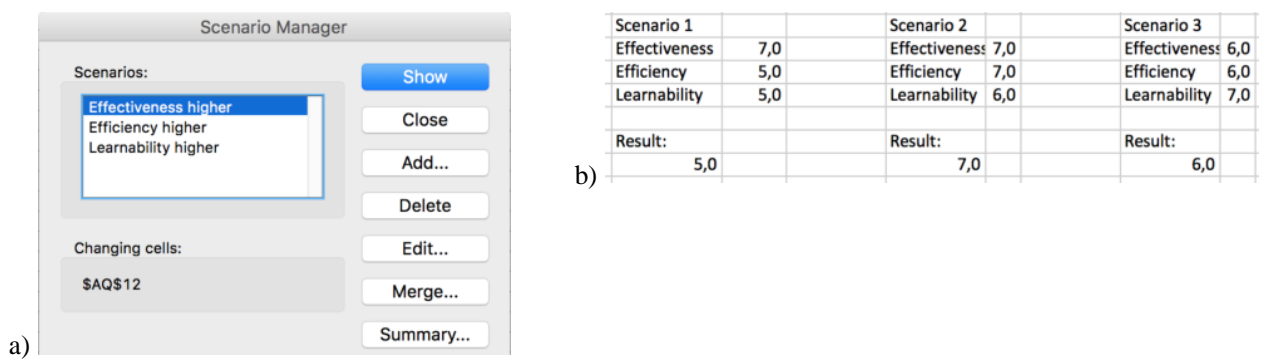

Figure 4. The scenario manager (a) and the outcome of goal-seek application (b)

\section{CONCLUSIONS AND FUTURE WORK}

In this paper we presented a case study, in which the central library Web site of the University of Minho was evaluated by a group of university students. As result of the analysis, some design improvements about constructs were suggested. We investigated how a research instrument can capture the usability of those Web sites. We also presented a structured methodology to both provide a multidimensional view of the analysis, as well as to perform additional analysis for verifying possible effects in hypothetical scenarios, analysing the system behaviour. We achieved the goals proposed in this paper, providing evidence that the usability of a Web site can be verified in terms of effectiveness, efficiency and learnability. We also provided evidence that DSS methods can be used to help extending the usability analysis, in order to help system designers and administrators to maintain and improve their systems.

In terms of limitation regarding the current research, we highlight the need to extend the end user participation to other university staff (e.g., library and department employees, etc.). This has the potential to increase the feedback regarding the usability aspects considered. Another aspect worth considering is the existing space for methodology improvement regarding the research instrument. While translating linear scale to order points might provide a reasonable simplified method for the respondent to situate his answer for the proposed question, it provides the researcher a smaller universe of space of analysis. Also, providing a nonresponse option (e.g., "no opinion") could provide an alternative for undecided respondents. Additionally automating the evaluation method would allow restoring the respective point scale related to each measurement, presenting order points to the interface designer. 
Future work in this research includes using the acquired knowledge for automating the process of analysis and increasing the complexity of the hypothetical scenarios. Additionally, adopting a different methodology for research instrument design might allow a wider range of measurements and therefore less limited universe of space of analysis.

\section{ACKNOWLEDGEMENT}

This work has been supported by Conselho Nacional de Pesquisa (CNPq), COMPETE: POCI-01-0145-FEDER-007043, and FCT - Fundação para a Ciência e Tecnologia within the Project Scope: UID/CEC/00319/2013. We also want to thanks to Instituto Federal de Educação, Ciência e Tecnologia de Goiás (IFG).

\section{REFERENCES}

Arh, T., \& Jerman-Blazic, B. (2007). Application of Multi-Attribute Decision Making Approach to Learning Management Systems Evaluation. JCP, 2(10), 28-37.

Babbie, E. (1999) The basics of social research. New York, NY: Wadsworth.

Benyon, D. (2014) Designing interactive systems: A comprehensive guide to HCI, UX and interaction design.

Breslin, M. (2004). Data warehousing battle of the giants. Business Intelligence Journal, 7, 6-20.

Casters, M., Bouman, R., \& Van Dongen, J. (2010). Pentaho Kettle solutions: building open source ETL solutions with Pentaho Data Integration. John Wiley \& Sons.

Djamasbi, S. Siegel, M. \& Tullis, T. (2010) Generation Y, web design, and eye tracking. International journal of human-computer studies, 68(5), 307-323.

Eklund, T., Tétard, F., Ståhl, P., Hirkman, P., \& Back, B. (2008, January). Usability evaluation of an XP product. In Proceedings of the 19 th Australasian Conference on Information Systems (ACIS) (pp. 280-289).

Excel (2019). Microsoft Excel. Available at https://products.office.com/pt-pt/excel?rtc=1 [Accessed June 19, 2019]

Fernandez, A. Insfran, E. \& Abrahão, S. (2011) Usability evaluation methods for the web: A systematic mapping study. Information and software Technology, 53(8), 789-817.

Fick, G., \& Sprague, R. H. (Eds.). (2013). Decision Support Systems: Issues and Challenges: Proceedings of an International Task Force Meeting June 23-25, 1980 (Vol. 11). Elsevier.

Golfarelli, M., Rizzi, S., \& Proli, A. (2006). Designing what-if analysis: towards a methodology. In Proceedings of the 9th ACM international workshop on Data warehousing and OLAP (pp. 51-58). ACM.

Hearst, M., \& Landay, J. (1999). Improving the Early Phases of Web Site Design via Informal Design Tools and Automated Usability Assessment.

ISO (2001). Standard 9126: Software Engineering Product Quality, parts 1, 2 and 3.

ISO/IEC (International Organization for Standardization) (1998). Standard 9241: Ergonomic Requirements for Office Work with Visual Display Terminals (VDT)s, Part 11. Guidance on Usability, Available at: https://www.iso.org/obp/ ui/\#iso:std:iso:9241:-11:ed-1:v1:en (accessed in 20 Jan 2019).

Ivory, M., \& Hearst, M. (1999). Comparing performance and usability evaluation: new methods for automated usability assessment. Submitted for publication.

Jeng, J. (2006). Usability of the digital library: An evaluation model. College and Research Libraries News, 67(2), 78.

Joo, S. (2010) How are usability elements-efficiency, effectiveness, and satisfaction-correlated with each other in the context of digital libraries? Proceedings of the American Society for Information Science and Technology, 47(1).

Joo, S. Lin S. \& Lu, K. (2011). A usability evaluation model for academic library websites: efficiency, effectiveness and learnability. Journal of Library and Information Studies, 9(2), 11-26.

Kimball, R. (1996). The data warehouse toolkit: practical techniques for building dimensional data warehouses (Vol. 1). New York: John Wiley \& Sons.

Kous, K. Pušnik, M. Heričko, M. \& Polančič, G. (2018). Usability evaluation of a library website with different end user groups. Journal of Librarianship and Information Science, 0961000618773133.

Leveson, N. (2011). Engineering a safer world: Systems thinking applied to safety. MIT press.

Matouk, K., \& Owoc, M. L. (2012, September). A survey of data warehouse architectures-Preliminary results. In 2012 Federated Conference on Computer Science and Information Systems (FedCSIS) (pp. 1121-1126). IEEE. 
Mazumder, F. K., \& Das, U. K. (2014). Usability guidelines for usable user interface. International Journal of Research in Engineering and Technology, 3(9), 79-82.

Muntean, M. I., \& Târnăveanu, D. (2012). A Multidimensional View Proposal of the Data Collected Through a Questionnaire. Associated Data Mart Deployment Framework. Database Systems Journal, 3(4), 33-46.

MySQL (2019). MySQL 8.0 Community Edition. Available at https://www.mysql.com/ [Accessed June 19, 2019]

MySQL Workbench (2019). MySQL Workbench 8.0. Available at https://www.mysql.com/products/workbench/. Available at https://www.forbes.com/sites/bernardmarr/2016/04/28/ big-data-overload-most-companies-cant-deal-with-the-dataexplosion/\#70cbd9506b0d [Accessed June 19, 2019]

Nielsen, J. (1994, April). Usability inspection methods. In Conference companion on Human factors in computing systems, (pp. 413-414). ACM.

Nielsen, J. (2003). Usability 101: Introduction to usability.

Okhovati, M. Karami, F. \& Khajouei, R. (2017). Exploring the usability of the central library websites of medical sciences universities. Journal of Librarianship and Information Science, 49(3), 246-255.

Pentaho (2019). Data Integration - Kettle. Hitachi Vantara Community. Available at https://community.hitachi vantara.com/docs/DOC-1009855-data-integration-kettle [Accessed June 19, 2019]

Root R. W. \& Draper S. (1983). Questionnaires as a software evaluation tool. In Proceedings of the SIGCHI conference on Human Factors in Computing Systems, December, pp. 83-87, ACM.

Rubinstein, R. Y., \& Kroese, D. P. (2016). Simulation and the Monte Carlo method (Vol. 10). John Wiley \& Sons.

Rungta, N., Brat, G., Clancey, W. J., Linde, C., Raimondi, F., Seah, C., \& Shafto, M. (2013, May). Aviation safety: modeling and analyzing complex interactions between humans and automated systems. In Proceedings of the 3rd international conference on application and theory of automation in command and control systems (pp. 27-37). ACM.

Turner, C. J., Hutabarat, W., Oyekan, J., \& Tiwari, A. (2016). Discrete event simulation and virtual reality use in industry: new opportunities and future trends. IEEE Transactions on Human-Machine Systems, 46(6), 882-894. 